ARTICLE

https://doi.org/10.1038/s41467-020-16601-1

\title{
Ultrahigh high-strain-rate superplasticity in a nanostructured high-entropy alloy
}

\author{
Nhung Thi-Cam Nguyen 1,2,4, Peyman Asghari-Rad (1) 1,2,4, Praveen Sathiyamoorthi (1) 1,2, Alireza Zargaran², \\ Chong Soo Lee ${ }^{3}$ \& Hyoung Seop Kim (1) ${ }^{1,2,3 凶}$
}

Superplasticity describes a material's ability to sustain large plastic deformation in the form of a tensile elongation to over $400 \%$ of its original length, but is generally observed only at a low strain rate $\left(10^{-4} \mathrm{~s}^{-1}\right)$, which results in long processing times that are economically undesirable for mass production. Superplasticity at high strain rates in excess of $10^{-2} \mathrm{~s}^{-1}$, required for viable industry-scale application, has usually only been achieved in low-strength aluminium and magnesium alloys. Here, we present a superplastic elongation to $2000 \%$ of the original length at a high strain rate of $5 \times 10^{-2} \mathrm{~s}^{-1}$ in an $\mathrm{Al}_{9}(\mathrm{CoCrFeMnNi})_{91}$ (at\%) highentropy alloy nanostructured using high-pressure torsion. The high-pressure torsion induced grain refinement in the multi-phase alloy combined with limited grain growth during hot plastic deformation enables high strain rate superplasticity through grain boundary sliding accommodated by dislocation activity.

\footnotetext{
${ }^{1}$ Department of Materials Science and Engineering, Pohang University of Science and Technology (POSTECH), Pohang 37673 , South Korea. ${ }^{2}$ Center for High Entropy Alloys, Pohang University of Science and Technology (POSTECH), Pohang 37673, South Korea. ${ }^{3}$ Graduate Institute of Ferrous Technology, Pohang University of Science and Technology (POSTECH), Pohang 37673, South Korea. ${ }^{4}$ These authors contributed equally: Nhung Thi-Cam Nguyen, Peyman Asghari-Rad. ${ }^{\bowtie}$ email: hskim@postech.ac.kr
} 
S uperplasticity is generally observed in fine-grained materials at low strain rates $\left(10^{-4}-10^{-3} \mathrm{~s}^{-1}\right)$ and high homologous temperatures $\left(>0.5 \mathrm{~T}_{\mathrm{m}}\right)$, where $\mathrm{T}_{\mathrm{m}}$ is the melting temperature $^{1-3}$. Over the past few decades, achieving superplasticity at high-strain rates $\left(>10^{-2} \mathrm{~s}^{-1}\right)$ has garnered wide attention from researchers as it possesses great advantage of reducing the forming time, making it economically viable for industries ${ }^{4,5}$. However, High Strain-Rate Superplasticity (HSRS) is extremely rare in high-strength materials, and in particular, the lack of superplastic forming capability in a recently emerged class of high-strength materials, the so-called High-Entropy Alloys (HEAs), is a serious obstacle for its potential use in engineering complex structures. HEAs have a unique alloy design concept based on multi-principle elements, and they exhibit remarkable properties such as high strength combined with high ductility as well as high fracture toughness when compared to conventional alloys $^{6-8}$. Thus, achieving HSRS in HEAs would signify a huge breakthrough in advanced material science.

According to the constitutive equation for superplasticity, a decrease in grain size is essential to achieve superplasticity at a high-strain rate res, $^{4,10}$. Besides, Grain Boundary Sliding (GBS), the predominant deformation mechanism found in superplastic behavior, is predominantly observed in materials with small grains and high-angle grain boundaries ${ }^{11,12}$. More importantly, retention of Ultra-Fine Grains (UFGs) or nanoscale grains without significant grain growth at elevated temperatures is essential to accommodate GBS and GBS-induced cavitation through diffusion or dislocation motion ${ }^{11,13,14}$. The representative CoCrFeMnNi HEA with a single Face-Centered Cubic (FCC) structure exhibited a reasonable superplastic elongation of $570 \%$ at elevated temperature ${ }^{15}$. There is a consensus that a multi-phase structure potentially shows higher elongation as compared with a single-phase structure due to grain growth suppression during the superplasticity test ${ }^{1,10}$. In most of the HEAs, the addition of $\mathrm{Al}$ has been demonstrated to form an ordered Body-Centered Cubic (B2) phase and it is shown to enhance the room temperature mechanical properties ${ }^{16-18}$. It has been reported that the B2 phase in $\mathrm{Al}_{\mathrm{x}}(\mathrm{CoCrFeMnNi})_{100-\mathrm{x}}$ forms when the $\mathrm{Al}$ content is above 8 at\%, and a drastic decrease in ductility is observed when the $\mathrm{Al}$ content is more than 11 at $\%^{19}$. Consequently, in the present study, we chose $\mathrm{Al}_{9}(\mathrm{CoCrFeMnNi})_{91}$ HEA based on the abovementioned logical reasoning and engineered a unique nanostructured dual-phase microstructure.

Here, we fabricate an $\mathrm{Al}_{9}(\mathrm{CoCrFeMnNi})_{91}$ HEA with nanosized FCC grains and B2 phase in the range of a few hundred nanometers to micrometers through thermo-mechanical treatment followed by high-pressure torsion (HPT) processing. Among several processing routes, the HPT is the most effective route to produce bulk materials with very fine grain size ${ }^{20-22}$. The presence of B2 phase and the newly formed sigma phase during superplastic testing assist in preventing significant grain growth, favoring GBS with high-strain-rate sensitivity value. The GBS is observed to be accommodated by interlinkage of cavities, and dislocation activities in FCC and B2 phases. The fine grain size accompanied by high-strain-rate sensitivity and GBS accommodation by plastic deformation lead to an ultra-high superplasticity of $2000 \%$ at a high-strain rate of $5 \times 10^{-2} \mathrm{~s}^{-1}$ in the present alloy. Considering the unique properties reported in HEAs and the HSRS achieved in the present work, HEAs show the potential to be an emerging advanced materials for future structural applications with complex shapes.

\section{Results and discussion}

Initial microstructure. The initial microstructure shows FCC and Al-Ni-rich B2 phases before superplastic tensile tests
(Fig. 1). The as-annealed specimen displays (Fig. 1a) fine FCC grains (average size of $\sim 2 \mu \mathrm{m}$ ) with relatively large B2 precipitates $(800 \mathrm{~nm}-1 \mu \mathrm{m})$ at the boundaries of FCC grains, and small B2 precipitates inside the FCC grains $(200-400 \mathrm{~nm})^{17,23,24}$. The XRay Diffraction (XRD) patterns of the as-annealed and as-HPT specimens show the peaks of FCC and B2 phases (Fig. 1b), we can see peak broadening occurs after HPT due to grain refinement and lattice distortion. The Backscattered Electron (BSE) image (Fig. 1c) displays how the B2 phase endured severe strain without a significant reduction in size after $\mathrm{HPT}^{23}$. Transmission Electron Microscopy (TEM) investigation with a corresponding Selected Area Electron Diffraction (SAED) pattern of the as-HPT specimen demonstrates the presence of a nanostructured FCC phase (Fig. 1d and Supplementary Fig. 1) as well as relatively fine B2 phase. Energy-Dispersive Spectroscopy (EDS) analysis reveals that the $\mathrm{B} 2$ phase is rich in $\mathrm{Al}$ and Ni. During the HPT process, the soft FCC grains undergo severe strain, which leads to significant grain refinement, and at the same time, the hard B2 phase flows alongside the soft FCC phase and retains its size ${ }^{23}$. This leads to a unique dual microstructure of nano-sized FCC matrix with a $\mathrm{B} 2$ phase in the range of a few hundred nanometers to micrometers.

Superplastic behavior. Figure 2a displays the representative engineering stress-strain curves under different testing conditions. The specimens fractured during tensile tests are shown in Fig. $2 \mathrm{~b}$ and Supplementary Fig. 2. Initially, elongation to failure lengths enhanced proportionally with increasing temperature with the elongation at $873 \mathrm{~K}$ being just $430 \%$. Then, superplastic elongation suddenly soared up to $1260 \%$ at $973 \mathrm{~K}$. The maximum elongation reached during our tests was $2000 \%$ at a temperature of $1073 \mathrm{~K}$ under a strain rate of $5 \times 10^{-2} \mathrm{~s}^{-1}$. Tensile deformed specimens at temperatures of 973 and $1073 \mathrm{~K}$ proceeded uniformly without any necking seen at any of the tested strain rates (Fig. 2b and Supplementary Fig. 2). The strain-rate sensitivity $(m)$ is a critical parameter used to characterize the ability of metals to resist necking during the deformation. The strain-rate sensitivity can be defined by $m=\partial \ln \sigma / \partial \ln \dot{\varepsilon}$, where $\sigma$ and $\dot{\varepsilon}$ denote the flow stress and plastic strain-rate, respectively. This is shown in Fig. 2c, where the squared $\mathrm{R}$ indicates the coefficient of determination. The estimated $m$ value increases with increasing temperature and is very close to the ideal value of 0.5 required for superplasticity at $1073 \mathrm{~K}^{1}$. Higher elongations at $973 \mathrm{~K}$ and $1073 \mathrm{~K}$, and relative lower elongation at $673 \mathrm{~K}$ could be attributed to the estimated $m$ values at these temperatures because high $m$ can decelerate the necking and assist homogeneous deformation ${ }^{25-27}$. The high value of $m$ also implies that the dominant mechanism of superplastic deformation is associated with GBS $^{1,28,29}$. Besides, HPT processing can produce nanoscale grains with a high fraction of high-angle boundaries, thus enabling GBS to occur easily ${ }^{30-32}$. The presence of quasi-stable flow is numerically verified by this $m$ value above and beyond the visual proof of the homogenous elongated specimen's gauge length.

To the best of our knowledge, the elongation to failure result of $2000 \%$ achieved in this work is the largest elongation ever reported for HEA and also represents a new record for elongation among the numerous HSRS investigations on conventional alloys ${ }^{10,33}$. Strikingly, the elongation to failure results achieved in this study using a high-strength material is even considered large when compared to conventional superplastic alloys that have low strength at room temperature $24,34-36$. The $2000 \%$ elongation in this study far exceeds the $1240 \%$ figure reported for wrought AlCoCrCuMnNi HEA ${ }^{10}$. Furthermore, the maximum elongation in this study $(2000 \%)$ was achieved at a lower temperature $(1073 \mathrm{~K})$ than for the AlCoCrCuMnNi HEA (1273 K) and with a far faster 

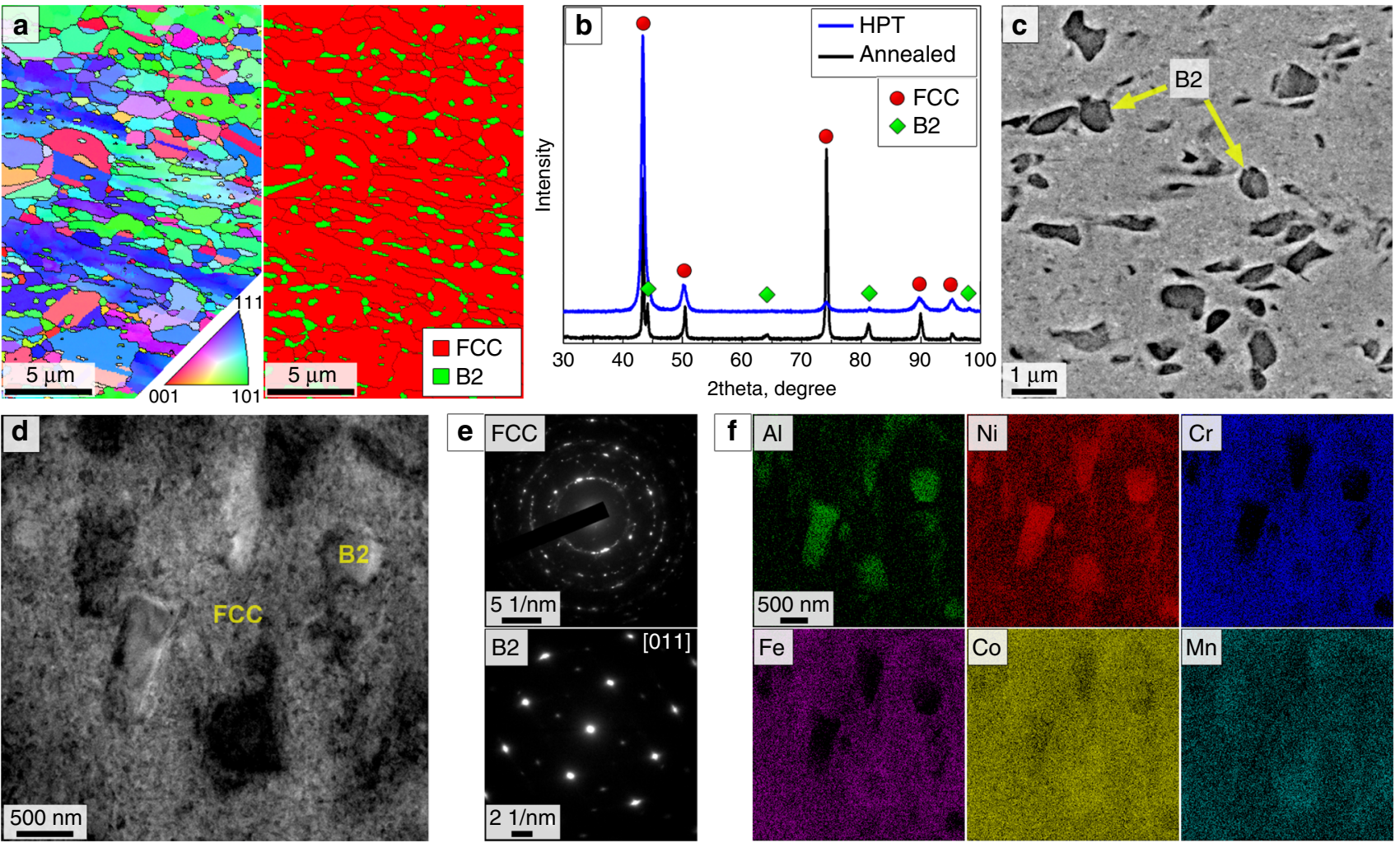

Fig. 1 Initial microstructure before superplasticity tests. a Electron Backscatter Diffraction (EBSD)-Inverse Pole Figure (IPF) map and corresponding phase map of annealed specimen, $\mathbf{b}$ X-Ray Diffraction (XRD) patterns of the annealed and High-Pressure Torsion (HPT) processed specimen, $\mathbf{c}$ Backscattered Electron (BSE) image of the as-HPT specimen, $\mathbf{d}$ Transmission Electron Microscopy (TEM) image of the as-HPT specimen, e Selected Area Electron Diffraction (SAED) patterns of Face-Centered Cubic (FCC) and ordered Body-Centered Cubic (B2) phases, $\mathbf{f}$ Transmission Electron Microscopy (TEM)-EnergyDispersive X-ray Spectroscopy (EDS) maps of the as-HPT specimen showing chemical distribution of the constituent elements.
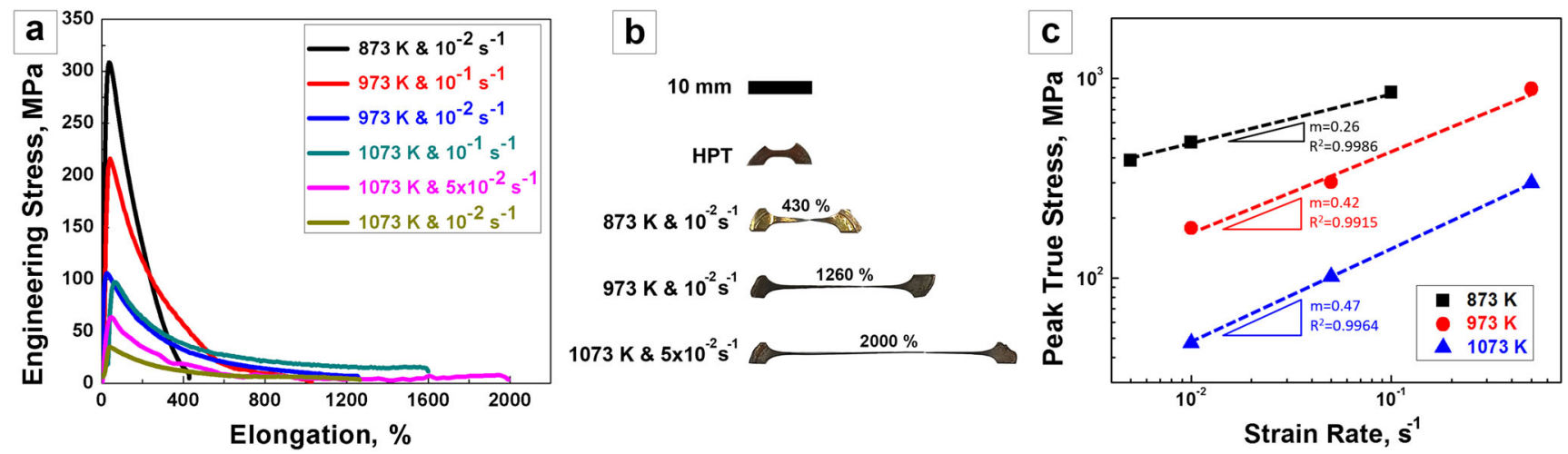

Fig. 2 Superplastic behavior of $\mathbf{A l}_{\mathbf{9}}\left(\mathbf{C o C r F e M n N i}_{\mathbf{9 1}}\right.$ high-entropy alloy (HEA). a Engineering stress-strain curves of tensile tests at 873,973, and $1073 \mathrm{~K}$ paired with various strain rates from $10^{-1}$ to $10^{-2} \mathrm{~s}^{-1}, \mathbf{b}$ Images of representative fractured specimens with their testing parameters, $\mathbf{c}$ Estimated strain-rate sensitivity $(m)$ from true stress against strain rate in double logarithmic scale.

strain rate of $5 \times 10^{-2} \mathrm{~s}^{-1}$ compared to $10^{-2} \mathrm{~s}^{-1}$ for $\mathrm{AlCoCr}-$ $\mathrm{CuMnNi}$. The liquidus temperature of AlCoCrCuMnNi, calculated from CALPHAD, is $1501 \mathrm{~K}$, and this is very similar to $1567 \mathrm{~K}$ of the present HEA (Supplementary Fig. 3). The difference in superplastic elongations at $1073-1273 \mathrm{~K}$ is notable for these HEAs during thermo-plastic processing ${ }^{10,37}$. From the domain of superplasticity research that utilizes HPT processing, the present HEA still has the best elongation result compared to the highest previously reported elongation of $1800 \%$ for illustrious $\mathrm{Zn}-22 \% \mathrm{Al}$ alloy ${ }^{38}$. It is worth mentioning that the high superplasticity seen in the present work was recorded for a tensile sample with a small cross-sectional area. It has been established in superplasticity literature on severely plastic deformed samples that small crosssectional area lead to relatively low elongation ${ }^{33}$. For instance, relatively higher elongation has been observed in $\mathrm{Zn}-22 \% \mathrm{Al}$ alloy processed by Equal-Channel Angular Pressing (ECAP) compared 


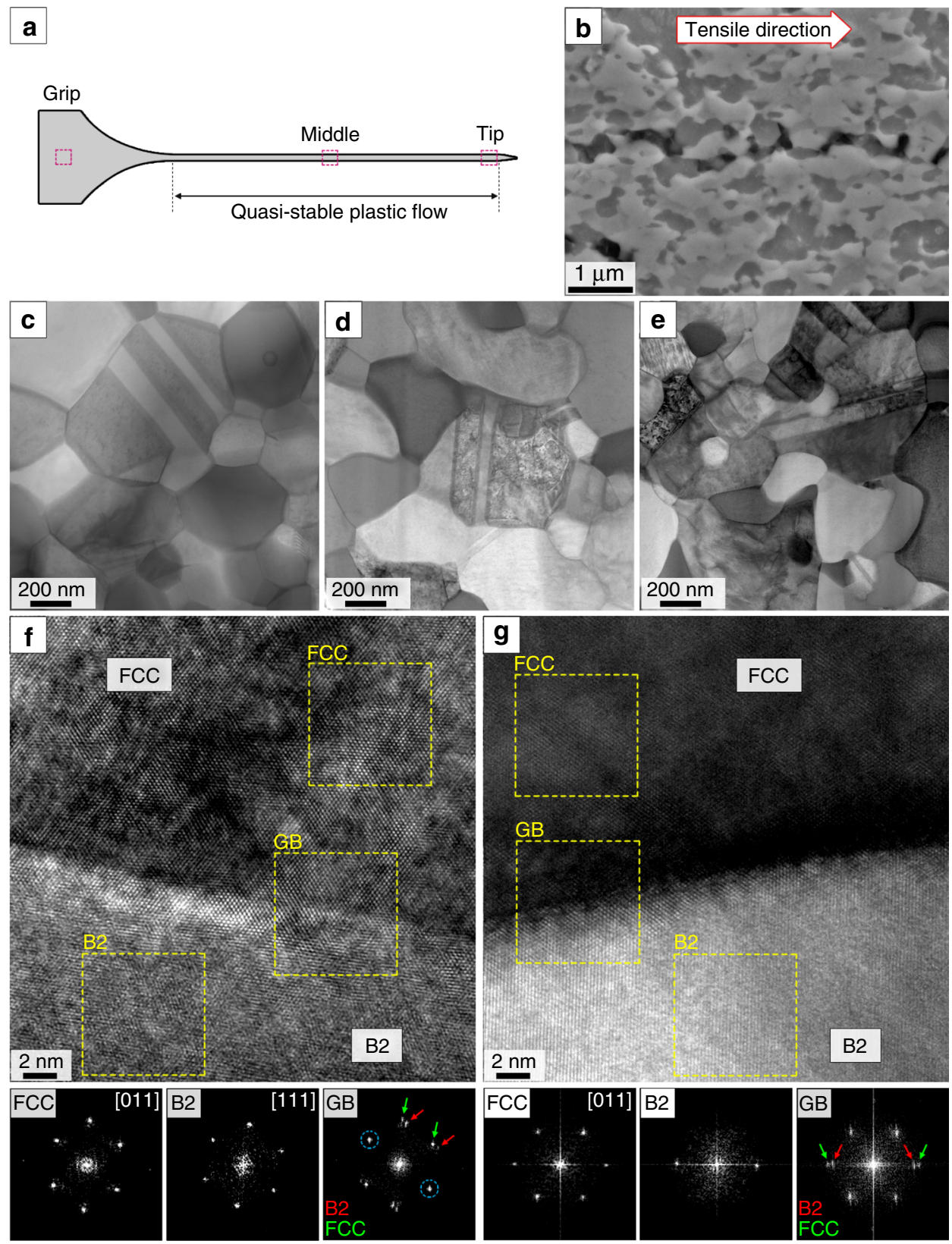

Fig. $\mathbf{3}$ Microstructural analysis of superplastic tensile specimen tested at $\mathbf{1 0 7 3} \mathbf{K}$ and $\mathbf{5} \times \mathbf{1 0}^{-\mathbf{2}} \mathbf{s}^{-\mathbf{1}}$. a Schematic illustration of superplasticity specimen with denoted positions for analysis, $\mathbf{b}$ BSE images of cavity strings from tip of the specimen, c-e Scanning Transmission Electron Microscopy (STEM) images from grip, middle and tip, (f, $\mathbf{g}$ ) High Resolution (HR)- TEM images from grip and tip with corresponding Fast Fourier Transform (FFT)- Selected Area Electron Diffraction (SAED) patterns. "GB" in $\mathbf{f}$, $\mathbf{g}$ stands for Grain Boundary.

to HPT-processed samples, this lower elongation in the HPTprocessed sample is attributed to its small cross-sectional area compared to the ECAP sample ${ }^{38}$.

Superplasticity mechanism. Microstructural investigations of the superplastic tensile sample at $2000 \%$ elongation from various positions along the deformed specimen are shown in Fig. 3. We can see the cavity strings are in alignment with the applied tension direction (Fig. 3b). Strikingly, the Scanning Transmission Electron Microscopy (STEM) images show that there is no considerable grain size difference between the deformed (gauge) and nondeformed (grip) parts (Fig. 3c-e), this indicates an almost total absence of dynamic grain growth in the deformed region ${ }^{39}$. The TEM-EDS analysis of the specimens tested at $1073 \mathrm{~K}$ shows the formation of sigma phase (rich in Cr) during the superplasticity tests in addition to the presence of FCC and B2 phases (Supplementary Fig. 4). The high-strain-rate and presence of B2 and sigma phases limit grain growth during superplastic deformation, leading to a quasi-theoretical $m$ value. Also, the grain morphology changes from an equiaxed shape at the grip to semiequiaxed morphology at the tip. High Resolution (HR)- TEM images from the interface of FCC and B2 phases at the grip are shown by Fig. $3 \mathrm{f}$ and at the tip are shown by Fig. 3g. Corresponding Fast Fourier Transform (FFT)- generated SAED patterns expose the presence of a Kurdjumov-Sachs (K-S) Orientation Relationship (OR; depicted by the blue circle) at the grip. However, there is no specific OR between FCC and B2 phases at the tip. 
Maintaining UFG and near-equiaxed morphology during the superplasticity test confirms the occurrence of $\mathrm{GBS}^{1}$. Elimination of OR between FCC and B2 points toward the occurrence of GBS that accommodates grain rotation during the superplasticity test ${ }^{40}$. In addition, the generation of the high dislocation density seen mainly in FCC and B2 grains (Supplementary Fig. 5) along with the evolution of the semi-equiaxed morphology at the tip suggests the role of intragranular dislocations for the accommodation of plastic deformation during the superplasticity test $^{9,41}$. However, the formation of intragranular dislocation in the sigma phase was not observed. The HR-TEM images taken from the interface show a high dislocation density around the interphase boundaries in the tip (Supplementary Figs. 6-8). Looking at the above evidence, we can say the different phases in the present multi-phase HEA demonstrate quite a heterogeneous mechanical response at the scale of individual grains during the superplasticity test. It can be concluded that the sigma phase may play the role of a hard domain in the present HEA and Geometrically Necessary Dislocations (GNDs) can be generated in the softer domains to maintain interphase boundary compatibility $^{42}$. Accordingly, the concurrent process of GBS and GBS being accommodated by intragranular dislocation and the generation of GNDs come together to contribute to the record elongation by postponing the initiation of cracks at interphase boundaries. A detailed survey on the superplasticity of HEAs shows that the accommodation of GBS by dislocation activity is rather limited ${ }^{43}$.

Cavity interlinkage. Cavity damage due to GBS can be restricted by the rare interlinkage of cavity strings under plasticitycontrolled cavity growth ${ }^{21,44}$. The width of cavity strings is on the order of grain size and originates at the interphase of FCC and B2 phases $^{9}$ (Supplementary Fig. 9). Cavities tend to grow along FCC grains parallel to the tensile direction and get blocked by B2 and sigma grains ${ }^{4,45}$. The ease of cavity interlinkage is manipulated by the interleaved microstructure of the present HEA, and this has the crucial impact of making it easy to retain quasi-stable plastic flow ${ }^{46}$. In HSRS, partial melting is suggested as one of the accommodation mechanisms to assist GBS due to the formation of a liquid-phase film at the boundaries ${ }^{47,48}$. However, TEM-EDS line-scanning at different interphase boundaries at the tip revealed a sharp change in the chemical compositions without any evidence of partial melting (i.e., segregation of an element or formation of an intermediate phase) at the boundaries in the present HEA (Supplementary Fig. 10).

In summary, this work shows that it is possible to achieve ultra-high HSRS in HEA through microstructural engineering. The formation of dual-phase microstructure during HPT and the subsequent formation of a sigma phase led to a multi-phase UFG microstructure during deformation. This UFG microstructure improves GBS efficiency leading to steady-state plastic flow and an estimated $m$ value close to the ideal value. In addition, the interlinkage of cavities and the dislocation motion in FCC and B2 phases reduce stress concentrations and play a vital role in accommodating GBS. Consequently, the present multi-phase microstructure is able to achieve an ultra-high HSRS with a the record of $2000 \%$ elongation that is significantly greater than anything seen in previous investigations from the severe plastic deformation society and HEA community. In addition, the unique properties of HEAs together with this ultra-high HSRS make HEAs even more attractive for aerospace and automobile industries. We propose that the practical improvement of superplasticity in HEA materials can be obtained by taking advantage of a multi-phase UFG structure.

\section{Methods}

Sample preparation and superplasticity tensile tests. The $\mathrm{Al}_{9}(\mathrm{CoCrFeMnNi})_{91}$ (at\%) HEA was produced from elements with a purity of $99.99 \%$ by vacuum induction melting. The as-cast ingot was homogenized at $1473 \mathrm{~K}$ for $12 \mathrm{~h}$, followed by water quenching. The ingot was subjected to cold-rolling to reduce its thickness from 7 to $1.5 \mathrm{~mm}$, and this corresponds to a $78.6 \%$ reduction. The cold-rolled ingot was annealed at $1273 \mathrm{~K}$ for $15 \mathrm{~min}$ in argon gas, followed by water quenching. Discs with a diameter of $10 \mathrm{~mm}$ were machined from the annealed plate through electric discharge machining. The $10 \mathrm{~mm}$ discs were processed by five revolutions of HPT at room temperature under an applied pressure of $6 \mathrm{GPa}$ with an anvil rotation rate of 1 revolution per minute.

Differential Scanning Calorimetry (DSC) measurements, using the SETARAM LABSYS evo DTA/DSC instrument, were conducted on a piece of the HPTprocessed sample $(\sim 100 \mathrm{mg})$. The HPT sample was loaded into a ceramic pan and then heated from room temperature to melting temperature with a heating rate of $10 \mathrm{~K} / \mathrm{min}$ in a nitrogen gas atmosphere. The flow rate of the $\mathrm{N} 2$ gas was controlled to remain at $50 \mathrm{~mL} / \mathrm{min}$. The absolute melting temperature from DSC was employed to determine the testing temperatures used in the superplasticity experiments.

Flat dog-bone-shaped specimens were machined symmetrically from the asHPT disks with the gauge's position set at $2.5 \mathrm{~mm}$ away from the center. The gauge dimensions are $1.5 \mathrm{~mm}$ in length, $1.0 \mathrm{~mm}$ in width, and $0.7 \mathrm{~mm}$ in thickness. The specimens were firmly assembled to a pair of nonslippery clamps at the grip parts by nuts, then subjected to tension tests using an Instron 8862 instrument. The specimens were well aligned to be parallel with the pulling shaft. The specimens were heated from room temperature to the target superplastic testing temperatures of 873,973 , and $1073 \mathrm{~K}$ by halogen furnace (DF-60HG, DaeHeung Co., Korea) in the air atmosphere. After the stabilization of temperature with a dwell time of $7 \mathrm{~min}$, the specimens were preloaded until $5 \mathrm{~N}$ to remove the thermal expansion effect of the system. Then, a traction load was applied until the fracture. The failure specimens were promptly immersed in water to preserve their microstructure. Three tests were carried out in each condition to ensure the reproducibility of results. The elongation was measured using the recorded displacement from the Instron data with a step size of $1 \mathrm{~s}$ on each different strain rate. In addition, the obtained elongation values were confirmed by evaluating the superplastic fractured samples using an optical microscope.

Microstructural characterization. The Transmission Electron Microscope (TEM) specimens of the as-HPT and grip of the superplastic specimens were prepared by mechanical grinding to a thickness of $\sim 60 \mu \mathrm{m}$, and they were then thinned using electro-polishing with a solution of $10 \% \mathrm{HClO}_{4}$ and $90 \% \mathrm{CH}_{3} \mathrm{COOH}$ at an applied voltage of $25 \mathrm{~V}$ at room temperature. The TEM foils from the middle and tip of superplastic specimens were carried out using the Focused Ion Beam (FIB) lift-out procedure. The TEM analysis was undertaken by the JEM-2100F (JEOL, Japan) instrument.

The surface of specimens was polished to a mirror-like finish using diamond paste and colloidal silica suspension for the following analysis.

Phase identification was determined by X-Ray Diffraction (XRD) using the Rigaku D/MAX-2500 XRD instrument employing $\mathrm{Cu}$ Ka radiation with a wavelength of $0.154 \mathrm{~nm}$. The XRD pattern was acquired in a $2 \theta$ range of $30-100^{\circ}$ at a scan rate of $1^{\circ}$ per min and a scan-interval of $0.02^{\circ}$.

The microstructure of the annealed specimen was observed using Electron Backscatter Diffraction (EBSD), performed by a Field Emission-Scanning Electron Microscope (FE-SEM; Quanta 3D, FEI Company, USA). The obtained data were analyzed using Orientation Imaging Microscopy (OIM) analysis software (TSL OIM analysis 7).

\section{Data availability}

The data that support the findings of this study are available from the corresponding author upon reasonable request.

Received: 19 February 2020; Accepted: 13 May 2020;

Published online: 01 June 2020

\section{References}

1. Langdon, T. G. Seventy-five years of superplasticity: historic developments and new opportunities. J. Mater. Sci. 44, 5998-6010 (2009).

2. McFadden, S. X., Mishra, R. S., Valiev, R. Z., Zhilyaev, A. P. \& Mukherjee, A. K. Low-temperature superplasticity in nanostructured nickel and metal alloys. Nature 398, 684-686 (1999).

3. Berdichevskij, E. G. Use of the superplasticity effect of materials in engineering technology. IOP Conf. Ser. Mater. Sci. Eng. 441, 012009 (2018).

4. Park, K. T., Hwang, D. Y., Lee, Y. K., Kim, Y. D. \& Shin, D. H. High strain rate superplasticity of submicrometer grained $5083 \mathrm{Al}$ alloy containing scandium fabricated by severe plastic deformation. Mater. Sci. Eng. A 341, 273-281 (2003). 
5. Musin, F., Kaibyshev, R., Motohashi, Y. \& Itoh, G. High strain rate superplasticity in a commercial Al-Mg-Sc alloy. Scr. Mater. 50, 511-516 (2004).

6. Ye, Y. Z., Wang, Q., Lu, J., Liu, C. T. \& Yang, Y. High-entropy alloy: challenges and prospects. Mater. Today 19, 349-362 (2016).

7. Zhang, Y. et al. Microstructures and properties of high-entropy alloys. Prog Mater. Sci. 61, 1-93 (2014)

8. Praveen, S. \& Kim, H. S. High-entropy alloys: potential candidates for hightemperature applications-an overview. Adv. Eng. Mater. 20, 1700645 (2018).

9. Kim, B. N., Hiraga, K., Morita, K. \& Sakka, Y. A high-strain-rate superplastic ceramic. Nature 413, 288-291 (2001)

10. Shaysultanov, D. G., Stepanov, N. D., Kuznetsov, A. V., Salishchev, G. A. \& Senkov, O. N. Phase composition and superplastic behavior of a wrought AlCoCrCuFeNi high-entropy alloy. JOM 65, 1815-1828 (2013).

11. Mohamed, F. A. Creep and superplasticity: evolution and rationalization. $A d v$. Eng. Mater. 22, 1900532 (2020).

12. Watanabe, T., Tsurekawa, S., Kobayashi, S. \& Yamaura, S. Structuredependent grain boundary deformation and fracture at high temperatures. Mater. Sci. Eng. A 410, 140-147 (2005).

13. Chokshi, A. H. \& Langdon, T. G. A model for diffusional cavity growth in superplasticity. Acta Metall. 35, 1089-1101 (1987).

14. Wei, Y., Bower, A. F. \& Gao, H. Recoverable creep deformation due to heterogeneous grain-boundary diffusion and sliding. Scr. Mater. 57, 933-936 (2007).

15. Shahmir, H., He, J., Lu, Z., Kawasaki, M. \& Langdon, T. G. Evidence for superplasticity in a CoCrFeNiMn high-entropy alloy processed by highpressure torsion. Mater. Sci. Eng. A 685, 342-348 (2017).

16. Choudhuri, D. et al. Enhancing strength and strain hardenability via deformation twinning in fcc-based high entropy alloys reinforced with intermetallic compounds. Acta Mater. 165, 420-430 (2019).

17. Chen, S. et al. Temperature effects on the serrated behavior of an Al0.5CoCrCuFeNi high-entropy alloy. Mater. Chem. Phys. 210, 20-28 (2018).

18. Sathiyamoorthi, P. et al. Achieving high strength and high ductility in Al0.3CoCrNi medium-entropy alloy through multi-phase hierarchical microstructure. Materialia 8, 100442 (2019).

19. He, J. H. et al. Effects of $\mathrm{Al}$ addition on structural evolution and tensile properties of the FeCoNiCrMn high-entropy alloy system. Acta Mater. 62, 105-113 (2014).

20. Asghari-Rad, P. et al. Effect of initial grain size on deformation mechanism during high-pressure torsion in V10Cr15Mn5Fe35Co10Ni25 high-entropy alloy. Adv. Eng. Mater. 22, 1900587 (2020).

21. Nguyen, N. T.-C. et al. Superplasticity of V10Cr15Mn5Fe35Co10Ni25 highentropy alloy processed using high-pressure torsion. Mater. Sci. Eng. A 764, 138198 (2019).

22. Asghari-Rad, P. et al. Fine-tuning of mechanical properties in V10Cr15Mn5Fe35Co10Ni25 high-entropy alloy through high-pressure torsion and annealing. Mater. Sci. Eng. A 771, 138604 (2020)

23. Reddy, T. S. et al. Severe plastic deformation driven nanostructure and phase evolution in a Al0.5CoCrFeMnNi dual phase high entropy alloy. Intermetallics 91, 150-157 (2017).

24. Park, J. M. et al. Effect of annealing heat treatment on microstructural evolution and tensile behavior of Al0.5CoCrFeMnNi high-entropy alloy. Mater. Sci. Eng. A 728, 251-258 (2018).

25. Hart, E. W. Theory of the tensile test. Acta Metall. 15, 351-355 (1967).

26. Wei, Y. \& Gao, H. An elastic-viscoplastic model of deformation in nanocrystalline metals based on coupled mechanisms in grain boundaries and grain interiors. Mater. Sci. Eng. A 478, 16-25 (2008).

27. Takai, R., Kimura, S., Kashichi, R., Kotaki, H. \& Yoshida, M. Grain refinement effects on the strain rate sensitivity and grain boundary sliding in partially solidified Al-5 wt\% Mg alloy. Mater. Sci. Eng. A 667, 417-425 (2016).

28. Nieh, T. G., Kaibyshev, R., Hsiung, L. M., Nguyen, N. \& Wadworth, J. Subgrain formation and evolution during the deformation of an Al-Mg-Sc alloy at elevated temperatures. Scr. Mater. 36, 1011-1016 (1997).

29. Pu, H. P., Liu, F. C. \& Huang, J. C. Characterization and analysis of lowtemperature superplasticity in 8090 Al-Li alloys. Metall. Mater. Trans. A 26, 1153-1166 (1995).

30. Park, K. T., Hwang, D. Y., Chang, S. Y. \& Shin, D. H. Low-temperature superplastic behavior of a submicrometer-grained $5083 \mathrm{Al}$ alloy fabricated by severe plastic deformation. Metall. Mater. Trans. A 33, 2859-2867 (2002).

31. Kawasaki, M. \& Langdon, T. G. Review: achieving superplasticity in metals processed by high-pressure torsion. J. Mater. Sci. 49, 6487-6496 (2014).

32. Fukutomi, H., Yamamoto, T., Nonomura, K. \& Takada, K. Examination of dislocation mechanism on grain boundary sliding in high angle grain boundaries by stress change test. Interface Sci. 7, 141-146 (1999).

33. Kawasaki, M. \& Langdon, T. G. The contribution of severe plastic deformation to research on superplasticity. Mater. Trans. 60, 1123-1130 (2019).

34. Nieh, T. G., Wadsworth, J. \& Sherby, O. D. Superplasticity in Metals and Ceramics. (Cambridge Univ. Press, Cambridge, 1997).
35. Kawasaki, M., Figueiredo, R. B. \& Langdon, T. G. The requirements for superplasticity with an emphasis on magnesium alloys. Adv. Eng. Mater. 18, 127-131 (2016).

36. Bhatta, L. et al. Recent development of superplasticity in aluminum alloys: a review. Metals 10, 77 (2020).

37. Yue, T. M., Xie, H., Lin, X., Yang, H. O. \& Meng, G. H. Solidification behaviour in laser cladding of AlCoCrCuFeNi high-entropy alloy on magnesium substrates. J. Alloy. Compd. 587, 588-593 (2014).

38. Kawasaki, M. \& Langdon, T. G. Developing superplasticity and a deformation mechanism map for the $\mathrm{Zn}-\mathrm{Al}$ eutectoid alloy processed by high-pressure torsion. Mater. Sci. Eng. A 528, 6140-6145 (2011).

39. Kim, B. N., Hiraga, K., Sakka, Y. \& Ahn, B. W. A grain-boundary diffusion model of dynamic grain growth during superplastic deformation. Acta Mater. 47, 3433-3439 (1999).

40. Clark, M. A. \& Alden, T. H. Deformation enhanced grain growth in a superplastic Sn-1\% Bi alloy. Acta Met. 21, 1195-1206 (1973).

41. Ball, A. \& Hutchison, M. M. Superplasticity in the Aluminum-Zinc eutectoid. Met. Sci. J. 3, 1-7 (1969).

42. Wu, X. \& Zhu, Y. Heterogeneous materials: a new class of materials with unprecedented mechanical properties. Mater. Res. Lett. 5, 527-532 (2017).

43. Chokshi, A. H. Grain boundary processes in strengthening, weakening, and superplasticity. Adv. Eng. Mater. 22, 1900748 (2020).

44. Nieh, T. G., Hsiung, L. M., Wadsworth, J. \& Kaibyshev, R. High strain rate superplasticity in a continuously recrystallized $\mathrm{Al}-6 \% \mathrm{Mg}-0.3 \% \mathrm{Sc}$ alloy. Acta Mater. 46, 2789-2800 (1998).

45. Leng, Z. et al. Superplastic behavior of extruded Mg-9RY-4Zn alloy containing long period stacking ordered phase. Mater. Sci. Eng. A 576, 202-206 (2013).

46. Langdon, T. G. Fracture processes in superplastic flow. Met. Sci. 16, 175-183 (1982).

47. Mabuchi, M. \& Higashi, K. On accommodation helper mechanism for superplasticity in metal matrix composites. Acta Mater. 47, 1915-1922 (1999).

48. Wakai, F. et al. A superplastic covalent crystal composite. Nature 344 421-423 (1990).

\section{Acknowledgements}

This investigation was supported by the Creative Materials Discovery Program through the National Research Foundation of Korea (NRF) granted by the Ministry of Science and ICT (2016M3D1A1023384). P.S. was funded by the Korea Research Fellowship program through the National Research Foundation of Korea (NRF) sponsored by the Ministry of Science and ICT (2017H1D3A1A01013666). We have gratefully received the advisory from Dr. Jongun Moon from POSTECH and Dr. Hamed Shahmir from the University of Sheffield, England.

\section{Author contributions}

N.T-C.N. and P.A-R. contributed equally to this work. N.T-C.N. generated the idea of superplastic alloy component and testing conditions, performed all experiments, processed data, and wrote the manuscript. P.A-R. conducted the sample preparation for superplastic tests (casting, rolling, HPT), performed the microstructural analysis using TEM and EBSD, and contributed to the writing and discussion part. S.P. supported the BSE and FIB implementation, revised the text, and contributed to the discussion. A.Z. contributed to the discussion part and accomplished the TEM works. C.S.L. provided the technical instruction for entire superplastic tensile tests. H.S.K. organized the work, supervised the research progress, and finalized the manuscript.

\section{Competing interests}

The authors declare no competing interests.

\section{Additional information}

Supplementary information is available for this paper at https://doi.org/10.1038/s41467 020-16601-1.

Correspondence and requests for materials should be addressed to H.S.K.

Peer review information Nature Communications thanks Peter Liaw and the other, anonymous, reviewer(s) for their contribution to the peer review of this work. Peer reviewer reports are available.

Reprints and permission information is available at http://www.nature.com/reprints Publisher's note Springer Nature remains neutral with regard to jurisdictional claims in published maps and institutional affiliations. 
(c) (i) Open Access This article is licensed under a Creative Commons Attribution 4.0 International License, which permits use, sharing, adaptation, distribution and reproduction in any medium or format, as long as you give appropriate credit to the original author(s) and the source, provide a link to the Creative Commons license, and indicate if changes were made. The images or other third party material in this article are included in the article's Creative Commons license, unless indicated otherwise in a credit line to the material. If material is not included in the article's Creative Commons license and your intended use is not permitted by statutory regulation or exceeds the permitted use, you will need to obtain permission directly from the copyright holder. To view a copy of this license, visit http://creativecommons.org/ licenses/by/4.0/.

(c) The Author(s) 2020, corrected publication 2022 